\title{
Prolapsos urogenitales: Revisión de conceptos
}

\author{
Palma P, Riccetto C, Hernández M, Olivares JM. \\ Servicio de Urología de la Facultad de Medicina de la Universidad Estatal de Campinas-Unicamp, Brazil.
}

Actas Urol Esp. 2008;32(6):618-623

\begin{abstract}
RESUMEN
PROLAPSOS UROGENITALES: REVISION DE CONCEPTOS

El prolapso genital es la exteriorización de los órganos pélvicos por la vagina, siendo una patología que afecta la calidad de vida de toda mujer, provocando, per sé, muy rara vez morbilidad o mortalidad. El prolapso genital se diagnostica en el 50\% de las mujeres multíparas y del 10 al20\% requiere tratamiento por su sintomatología.

Se calcula que una mujer, a lo largo de su vida, tiene $11 \%$ de riesgo de necesitar cirugía de corrección de prolapso de los órganos pélvicos o por incontinencia urinaria. Los prolapsos pueden ser de la pared anterior de la vagina (cistocele), de la cúpula vaginal, del útero (histerocele) o de su pared posterior (rectocele o enterocele). De acuerdo al estado general de la paciente y al trofismo de sus tejidos, se puede optar por cirugías obliterativas o reconstructivas, respectivamente. Teniendo en cuenta que para las cirugías reconstructivas se debe realizar, un adecuado diagnóstico, con el fin de poder corregir el defecto, ya sea en su pared anterior, posterior o cúpula, utilizando puntos de sutura, mallas biológicas o sintéticas.
\end{abstract}

Palabras clave: Prolapsos urogenitales. Cirugía de prolapsos. Disfunción del piso pélvico.

\section{ABSTRACT}

UROGENITALS PROLAPS: REVISION OF CONCEPTS

The prolapse is the exteriorization of the pelvic organs through the vagina, this condition may affect the quality of life. The prolapse was diagnosed in $50 \%$ of multiparous women It is estimated that a woman throughout her life, has $11 \%$ risk of needing surgery for correction of pelvic organ prolapse or urinary incontinence. The prolapse may occur at the anterior vaginal wall (cystocele) at the vaginal, uterus (histerocele) or at the posterior wall (or rectocele enterocele). For the unfit patient obliteratives procedures may be indicated and recontructives for pacients wih good performance status. It is important for reconstructive surgery a correct diagnosis, for the specific defect repair. When indicated, meshes can be used to add strength to the poor quality tissues.

Keywords: Urogenitals prolaps. Prolaps surgery. Pelvic floor dysfunction.

Q e considera que el riesgo de desarrollo de proDlapsos urogenitales se duplica en cada década de la vida. Debido a esto, en los últimos años, los trabajos de investigación modificaron significativamente la interpretación de la fisiopatología de los prolapsos, dando como resultando, nuevas propuestas para el diagnóstico y, sobre todo, el tratamiento quirúrgico ${ }^{1}$.

Debe considerarse que el tratamiento, también podría variar en función de la edad, condiciones clínicas de la paciente y perspectivas de vida sexual activa en el futuro.
Las cirugías obliterativas, tienen como objetivo, tratar el prolapso a través de la oclusión parcial o total de la vagina. Dependiendo de la exéresis o no del tejido vaginal, son denominadas, colpectomías o colpocleises, respectivamente. Presentan bajo índice de recidiva y complicaciones, sin embargo imposibilitan la actividad sexual futura, por ese motivo son indicadas predominantemente, en las mujeres añosas y con condiciones clínicas desfavorables (Fig. 1).

Los procedimientos reconstructivos, tienen como objetivo mantener la longitud, diámetro y el eje vaginal fisiológico, a fin de preservar la función 

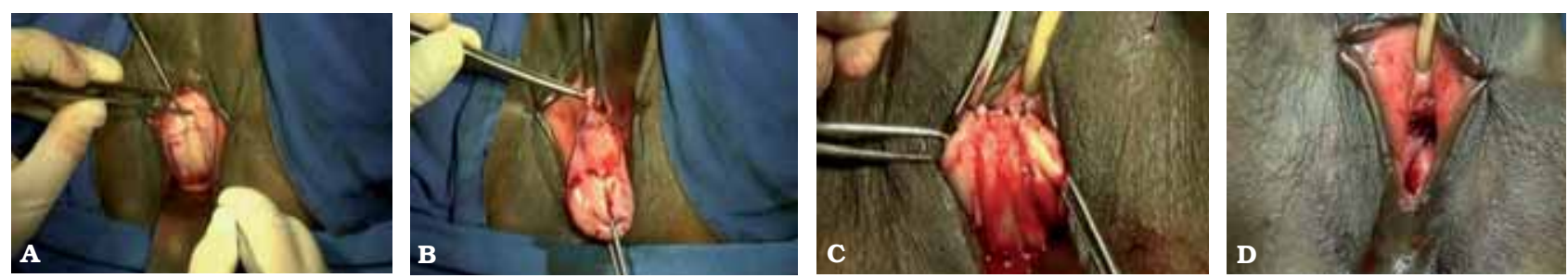

FIGURA 1. Colpocleisis según técnicr de Lê Fort. (A) exéresis de la pared vaginal posterior. (B) exéresis de la pared vaginal anterior. (C) invaginación del cuello uterino a través de la sutura de la pared vaginal anterior con la posterior. (D) aspecto final. En esta técnica permanecen los canales laterales abiertos que permiten la toma de material para citología oncológica del cuello uterino.

sexual, urinaria e intestinal. Los recientes avances en la comprensión de la estática y anatomía del suelo pélvico femenino, llevaron a la introducción del concepto del abordaje quirúrgico sitio específico, de los defectos responsables del prolapso genital. La necesidad de la corrección simultánea de todos los defectos, tiene como objetivo, un mejor resultado anatomo-funcional posible, exige que el cirujano pélvico tenga conocimiento de varias técnicas quirúrgicas, teniendo la desición final sobre la conducta tomada, muchas veces después de la disección intraoperatoria. De esta forma, se concluye con la combinación de técnicas quirúrgicas diferentes, sobre todo en los prolapsos acentuados.

Diversas técnicas reconstructivas han sido descriptas, asociadas con diferentes tasas de curación y relacionadas con riesgos específicos de complicaciones $^{2}$. De forma semejante, a las de las hernias de la pared abdominal, se tiene un consenso acerca de la deficiencia del tejido conjuntivo, como factor predisponente de la génesis primaria y de la recidiva póst-operatoria de los prolapsos urogenitales. Dicho factor determina el empleo creciente de las prótesis, de origen sintético o biológico, en detrimento de las técnicas convencionales, basadas exclusivamente en la corrección por medio de suturas. El empleo de prótesis permite, todavía, mejor estandarización de los procedimientos, disminución del tiempo quirúr- gico y mejor recuperación post-operatoria, haciendo posible la reinserción de la paciente a sus actividades habituales. Sin embargo, las contraindicaciones para el uso de prótesis, para reconstrucción del suelo pélvico todavía no se encuentran definitivamente establecidas, particularmente sus interacciones a largo plazo con la vejiga y el recto, así como sus posibles consecuencias sobre la función sexual. Así, su empleo se reserva para pacientes con prolapsos acentuados y con significativo compromiso residual, en los cuales, cualquier técnica basada exclusivamente en suturas de las estructuras lesionadas, resulta con elevados índices de recidiva.

\section{PROLAPSO DE LA PARED VAGINAL ANTERIOR}

Se considera actualmente que los prolapsos de la pared vaginal anterior, pueden ser por tres defectos diferentes, que pueden surgir de forma combinada: defecto pericervical, lateral y central ${ }^{3}$.

La importancia de la desinserción de la fascia vesicovaginal del anillo pericervical, fue por varios años sub-valorizada. Actualmente, sin embargo, se considera como altamente prevalente en los prolapsos vaginales anteriores ${ }^{4}$. Se trata por medio de suturas de la fascia en el anillo pericervical, asociada generalmente con colporrafía anterior o implante de prótesis (Figs. 2 y 3).
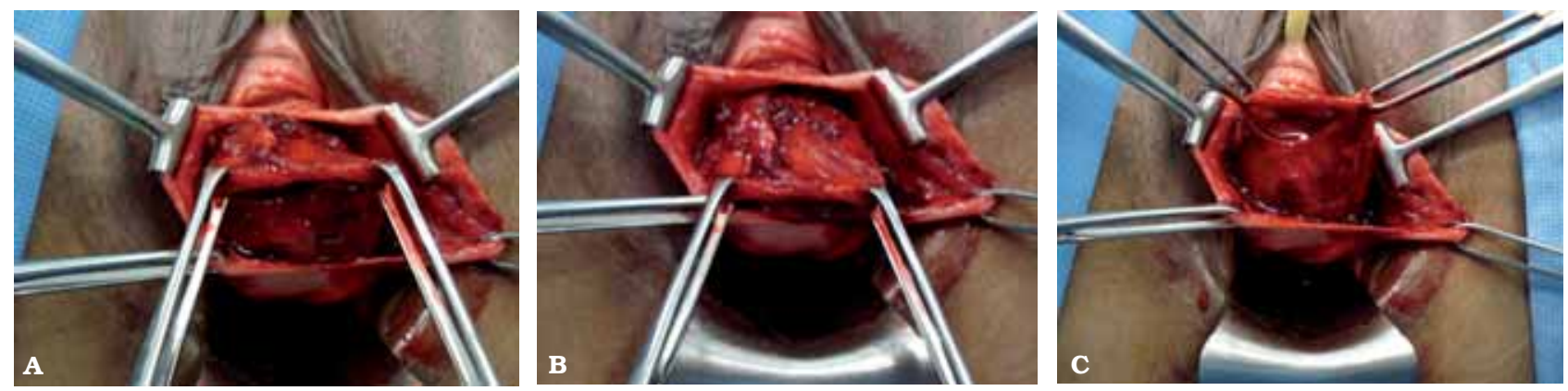

FIGURA 2. (A, B y C). Paciente con cistocele por defecto pericervical. Observe la fascia pubocervical disecada (reparada con Allis) y desinsertada de la cara anterior del cuello uterino. 


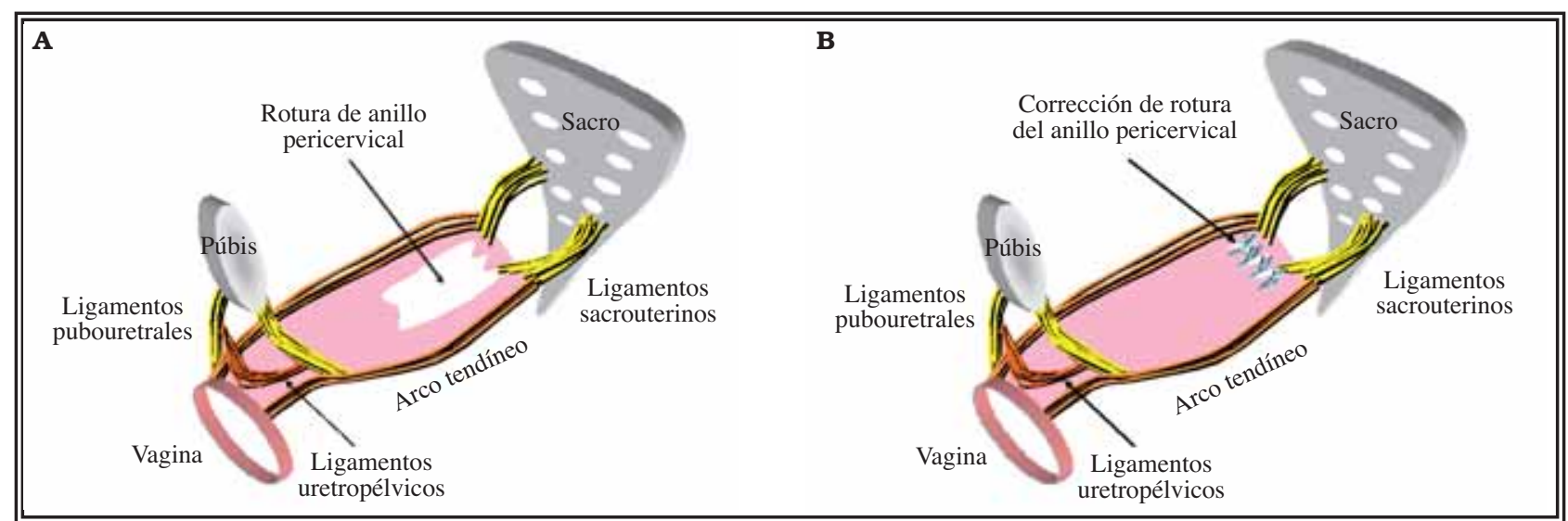

FIGURA 3. (A) Representación de la rotura de la inserción de la fascia pubocervical en la cara anterior del anillo pericervical. (B) Representación de la corrección quirúrgica.

Cuando la rotura de la fáscia vesicovaginal del arco tendíneo, es uni o bilateral, se verifica la desaparición de los surcos laterales de la pared vaginal anterior, y su tratamiento es realizado a través de la aplicación de suturas, del borde lateral de la fascia desinsertada, al arco tendíneo de la fáscia pélvica endopélvica $^{5}$ (Fig. 4).

La plicatura central de la fáscia pubocervical se emplea, generalmente, de forma asociada, a las correcciones descriptas anteriormente, cuando hay adelgazamiento central de la fascia (Fig. 5).

De forma alternativa, se puede optar por el empleo de prótesis, siendo la decisión tomada, muy importante, de acuerdo a la gravedad del prolapso y a las condiciones tróficas locales de las estructuras anatómicas.

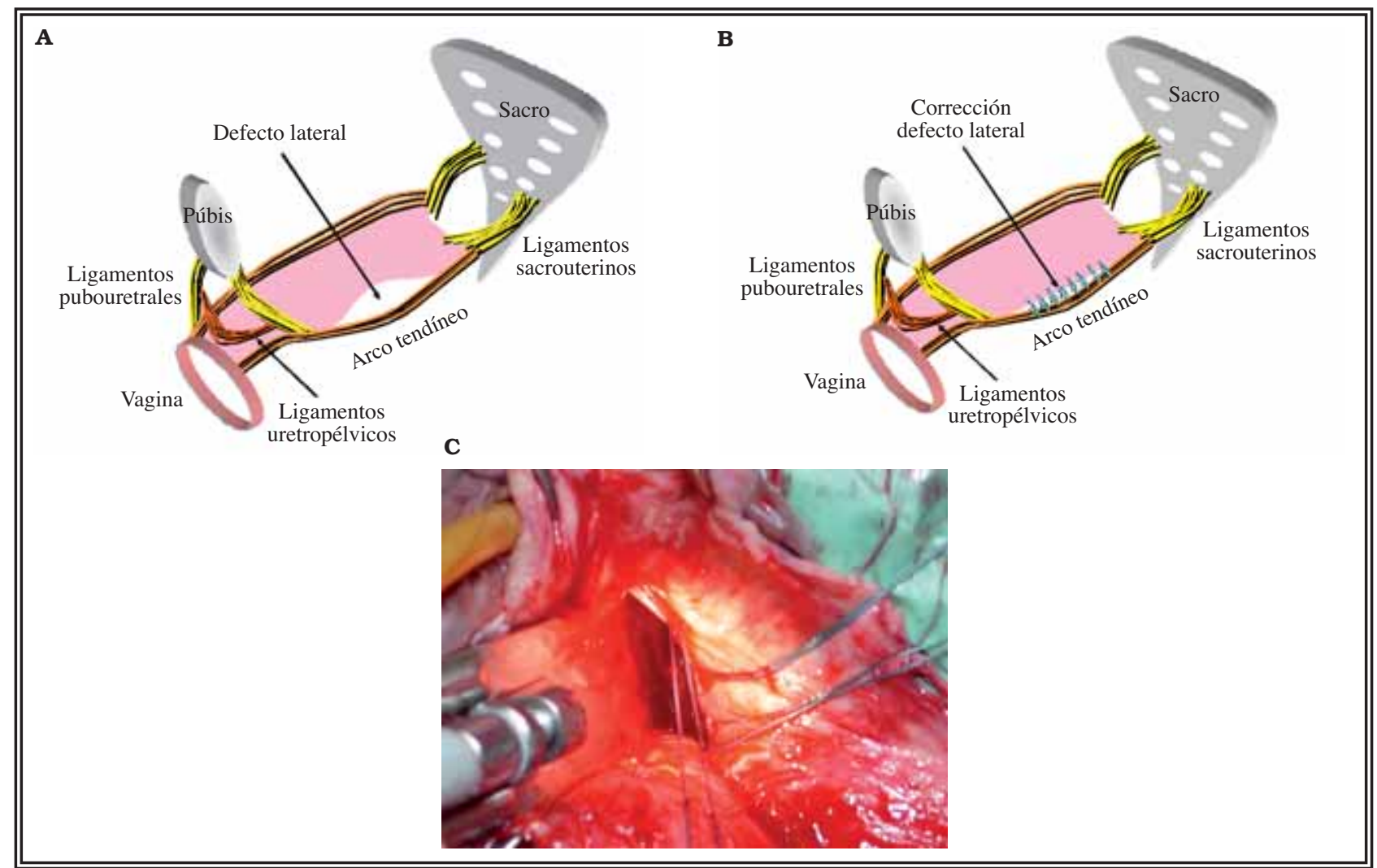

FIGURA 4. (A) Representación de la rotura de la inserción de la fáscia pubocervical en el arco tendíneo de la fáscia endopélvica. (B) Representación de la corrección quirúrgica. (C) Aspecto intra-operatorio de la aplicación de los puntos en el arco tendineo. 


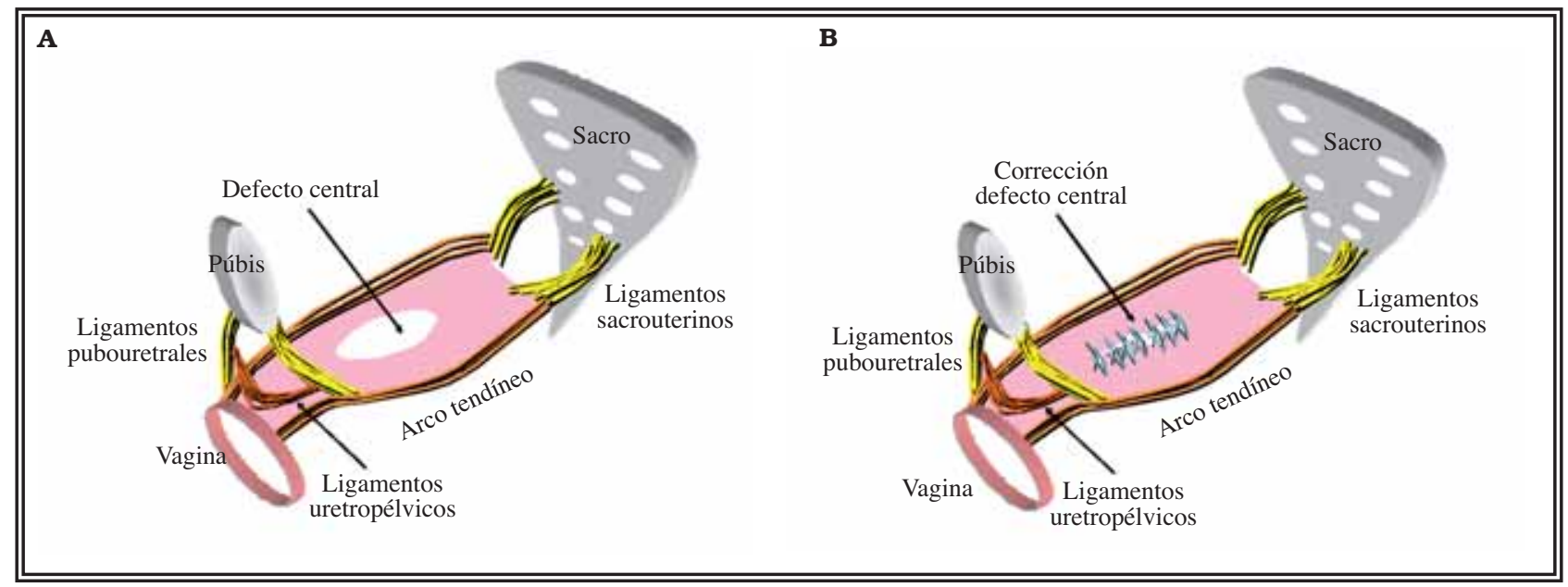

FIGURA 5. (A) Representación de lesión central de la fascia pubocervical. (B) Representación de corrección quirúrgica.

\section{PROLAPSO APICAL (ÚTERO O CÚPULA VAGINAL)}

En condiciones normales con la mujer en posición ortostática, el tercio superior de la vagina se encuentra en posición horizontal, reposando sobre la musculatura del diafragma pélvico. El ápice de la vagina se mantiene en esta posición por los ligamentos cardinales y sacrouterinos?. Sin embargo en la corrección de las distopías, se debe buscar reposicionar la vagina a la posición más próxima posible de la original, sea usando los ligamentos naturales de suspensión vaginal (cardinales y sacrouterinos), o empleando otros puntos de suspensión (tales como el ligamento sacroespinosos o a la fascia del músculo íleococcígeo) o, también, buscando la creación de neo-ligamentos por medio de prótesis. Las principales cirugías para la corrección de los prolapsos apicales son:

- Promonto fijación de la cúpula vaginal: consiste en fijar el ápice vaginal o el cuello del útero en el promontório sacro, generalmente con la interposición de malla de material sintético. El procedimiento puede ser realizado de forma convencional $\mathrm{y}$, recientemente, por vía laparoscópica. Se trata de una técnica muy difundida y adecuadamente estandarizada, con elevado índice de éxito, además de preservar parcialmente el eje vaginal. Presenta, como desventaja, la necesidad eventual de acceso combinado por vía vaginal para corrección de otros defectos asociados (Fig. 6).

- Fujación de la cúpula al ligamento sacroespinoso: Es la cirugía más utilizada en el tratamiento del prolapso apical, manteniendo el eje vaginal próximo al fisiológico, sin embargo dislocado lateralmente, con

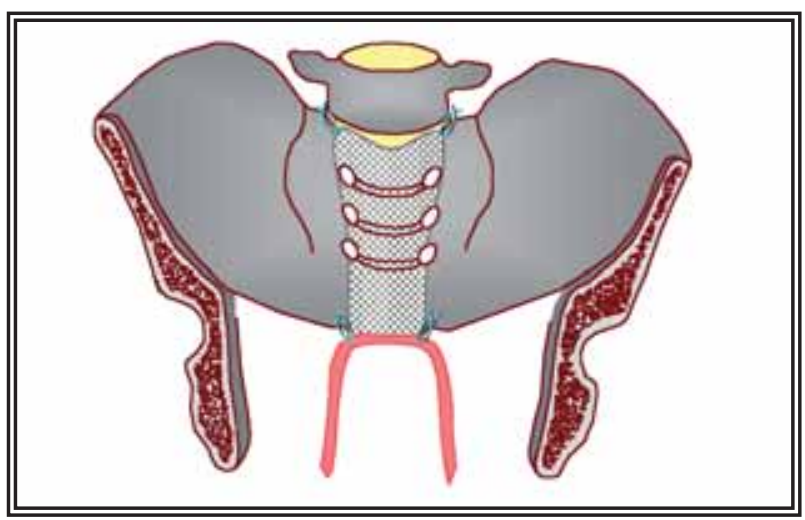

FIGURA 6. Representación esquemática de promonto fijación de la cúpula vaginal. Se emplea malla sintética o injerto de material biológico para fijación de la cúpula vaginal al promontório sacro.

alta tasa de cura. Generalmente es utilizado el ligamento sacroespinoso derecho, sin ser necesaria la fijación bilateral. Presenta como riesgo principal la posibilidad de lesión inadvertida de los vasos o nervio pudendos interno durante la aplicación de las suturas, con sangrado o dolor persistente en la nalga.

- Colpopexia transcoccígea: Se basa en el empleo de prótesis de polipropileno en forma de cinturón, que son aplicadas bilateralmente a través de punciones cutáneas en la fosa ísquiorrectal y fijadas a la cúpula vaginal, a nivel de los ligamentos sacroespinosos. Tiene como objetivo reproducir la fijación natural concedida por los ligamentos sacrouterinos. Ese procedimiento fue descripto recientemente, y presenta como ventaja la facilidad técnica, así como también mantener el eje vaginal fisiológico. Puede ser empleada, en conjunto, con mallas para corrección de rectoceles y de enteroceles (Fig. 7). 


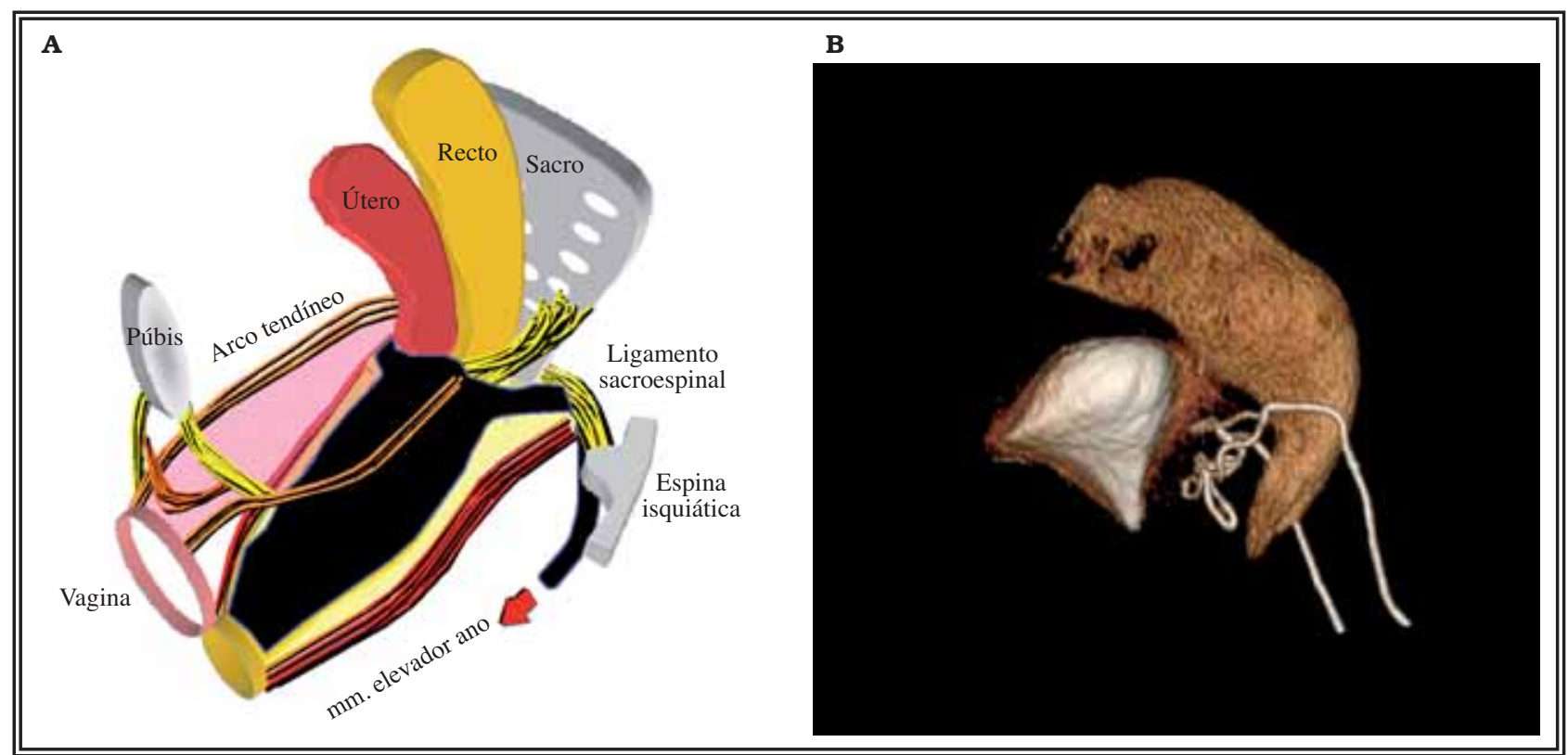

FIGURA 7. Colpopéxia transcoccígea. (A) Representación esquemática. Observe que las astas de la prótesis son ancladas en los ligamentos sacroespinosos. (B) Tomografia tridimensional de perfil evidenciando la prótesis radiopaca (en blanco) al frente del recto. Observe las astas que sustituyen la función de los ligamentos sacrouterinos.

\section{CORRECCION DE LOS PROLAPSOS DE LA PARED POSTERIOR}

El septo rectovaginal se condensa alrededor del cervix uterino, posteriormente, en conjunto con los ligamentos sacrouterinos, cardinales y la fascia endopélvica, formando una estructura llamada anillo pericervical. A partir del anillo pericervical, el septo rectovaginal se extiende en dirección al cuerpo perineal. Lesiones de esta estructura llevan a la formación de rectocele y/o enterocele ${ }^{3}$ (Fig. 8).

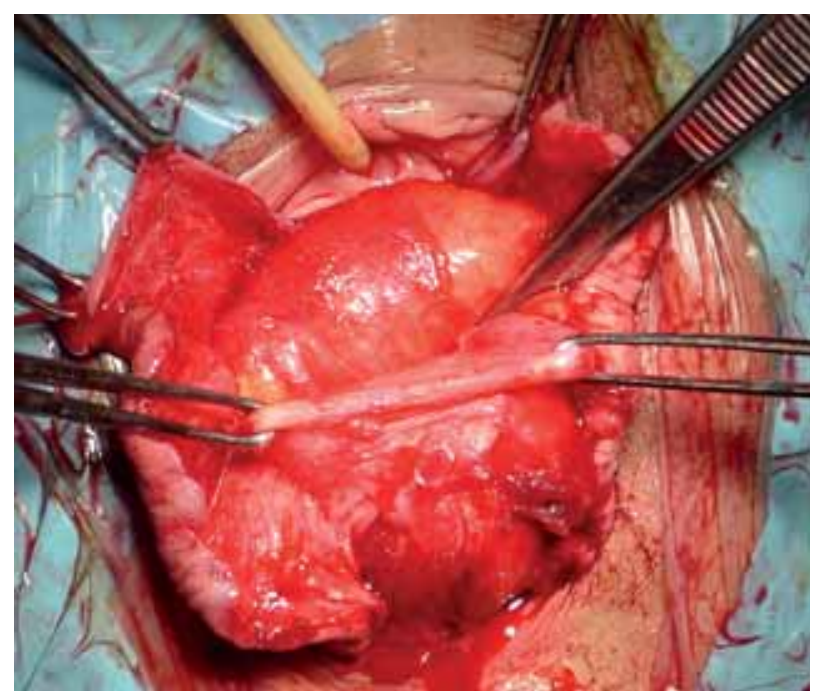

FIGURA 8. Disección intra-operatoria evidenciando la transición entre el recto y el septo rectovaginal lesionado.
Durante varios años, la miorráfia de los elevadores del ano, fue la técnica más empleada para su corrección. Se asocia con un largo período de recuperación post-operatoria, en virtud del dolor resultante de la plicatura anti-anatómica de la musculatura del elevador del ano, anterior al recto. Se trata de una técnica no fisiológica, debido a que la musculatura elevadora del ano no se localiza anteriormente al recto en la mujer normal, además de asociarse con un elevado índice de recidiva, encontrándose ya en desuso ${ }^{6}$.

La desinserción del septo rectovaginal del anillo pericervical, generalmente, ocurre posterior a partos vaginales, en los cuales, la insinuación del occipucio fetal, se dirige posteriormente a la pelvis (ej.: insinuación occipito-sacra). La desinserción del septo rectovaginal puede llevar a la formación de enterocele y rectocele proximal, es considerada, actualmente, la principal causa fisiopatológica de los defectos posteriores y apicales de la vagina. En la reconstrucción del anillo pericervical, la pared vaginal posterior es disecada, desde la horquilla vaginal hasta el fondo de saco vaginal posterior, procurando identificar el septo rectovaginal desinsertado, el cual, generalmente se encuentra retraído en el tercio distal de la vagina. Inmediatamente el septo es suturado a los ligamentos sacrouterinos y a la cara posterior del cuello uterino, así se reconstituye el anillo pericervical (Fig. 9). 


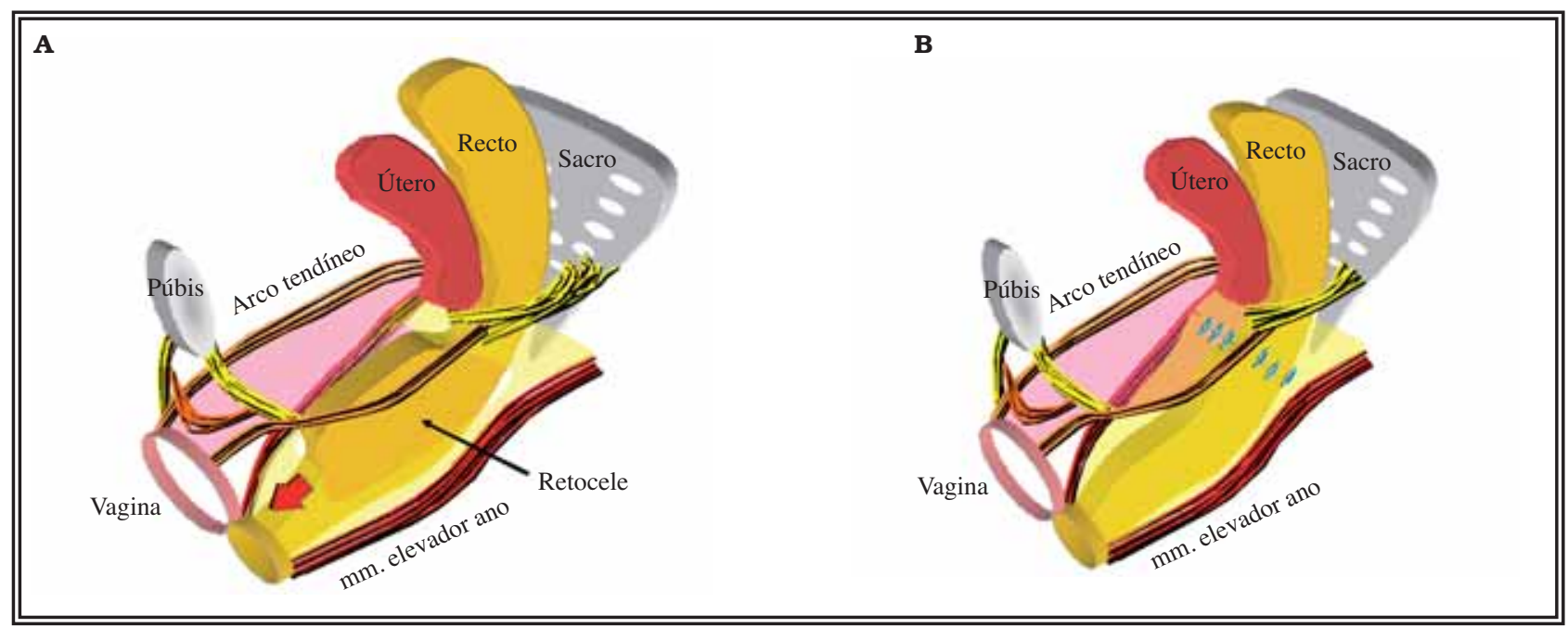

FIGURA 9. (A) Representación esquemática del rectocele por lesión de la inserción del septo rectovaginal del anillo $l$ pericervical y su corrección (B).

En grandes prolapsos, en los cuales, las condiciones del septo rectovaginal son malas, pueden ser empleadas prótesis para la reconstrucción de la pared vaginal posterior, con la técnica de colpopéxia transcoccígea ya descrpita, utilizándose prótesis ancladas bilateralmente a los ligamentos sacroespinosos, presentando prolongaciones que son aplicadas al recto y fijadas en el septo rectovaginal a nivel del introito vaginal. A pesar del empleo, todavía restringido, la posibilidad de corrección combinada del defecto apical y posterior, convierte a esta técnica, particularmente importante en los prolapsos acentuados.

Debe considerarse, generalmente, que los defectos de la pared vaginal posterior, se asocian a grados variables de rotura del cuerpo perineal. Su lesión se manifiesta por el adelgazamiento del conjunto muscular entre la horquilla vaginal y el ano. $\mathrm{Su}$ reconstrucción se realiza por medio de suturas en el septo rectovaginal distal y en los músculos bulbocavernosos. Las roturas perineales pueden llevar a la formación de rectocele distal (que disecan la región perineal). La perineorráfia, con recons- trucción del cuerpo perineal, abarcando el septo rectovaginal, corrige esta distopía y restituye el introito vaginal a sus dimensiones normales.

\section{REFERENCIAS}

1. Bump RC, Mattiasson A, Bø K, Brubaker LP, DeLancey JO, Klarskov P, et al. The standardization of terminology of female pelvic organ and pelvic floor dysfunction. Am J Obstet Gynecol. 1996;175(1):10-17.

2. Castro EB, Palma PCR, Herrmann V et al. Aspectos Atuais no Tratamento do Prolapso de Cúpula Vaginal. Femina 2005;33: 187-92.

3. Wei JT, De Lancey JO. Functional anatomy of the pelvic floor and lower urinary tract. Clin Obstet Gynecol 2000;47(1):3-17.

4. Palma PCR, Netto JR, NR. Uroginecologia Ilustrada. 2005, Editora Roca, São Paulo, pág 236-239.

5. Oscar Contreras Ortiz, Paulo Palma, Viviane Herrmann. Uroginecologia, Editora CAU, Caracas, 2006. 29:177-184.

6. Biagio Adile, Elizabetta Constantini, Sebastiano Bandiera. Uroginecología, Editora CAU, Caracas, 2006. 30:177-184.

Correspondencia autor: Dr. P. Palma

Servicio de Urología. Facultad de Medicina de la Universidad

Estatal de Campinas-Unicamp. Brazil. Tel.: +55 1935217481

E-mail autor: ppalma@uol.com.br

Información artículo: Revisión - Urología femenina

Trabajo recibido: febrero 2008

Trabajo aceptado: marzo 2008 